\title{
Mental Health on University Campuses and the Needs of Students They Seek to Serve
}

Leah Goodman, MA, OTR/L

The University of Illinois at Chicago

\begin{abstract}
Background: The mental health of college students in the U.S. has become an undeniable concern to university administrators, service providers, and the higher education community at large. While universities seek to educate future great minds, their current policies and infrastructure do not unanimously prioritize mental health, thus, they often cannot meet the holistic needs of students and struggle to uphold their central mission.

Aim: To outline the literature surrounding mental health in postsecondary education and the holistic needs of university students in order to target the national discussion of mental health toward actionable system change.

Methods: A comprehensive review of the literature on college student mental health in the U.S.

Results: The literature demonstrates that policy change is necessary to fully support students with psychiatric disabilities and mental health concerns.

Conclusions: Mental health is a critical issue for young adults, and college presents a prime developmental context to equip students with the skills for a lifetime of mental health and wellbeing. Further research is needed to explore the impact of implementing innovative programs, curricular changes and supported education programs to support college students.
\end{abstract}

Submitted 5 September 2017: accepted 2 October 2017

Keywords: mental health, higher education, policy change, disability, wellbeing

The transition to college and full participation in the student role radically changes the dynamic of daily life and responsibility. Students are abruptly burdened with increased levels of stress, anxiety and depression, and they can be overwhelmed as they attempt to independently navigate a novel experience (Dickson \& Gullo, 2015Kreider, Bendixen, \& Lutz, 2015). The demands upon students can supersede their ability to cope, compounded, in many instances, by preexisting or newly manifesting psychiatric symptoms.

Mental health is a critical concern on college campuses. According to the American College Health Association, 86\% of college students report feeling overwhelmed by their responsibilities; $57 \%$ experience substantial anxiety; almost 35\% describe feeling so depressed that it becomes difficult to function; and approximately $66 \%$ suffer academically due to either depression, anxiety or stress (American College Health Association, 2015; Brown, 2016). The overwhelming majority of students on campus experience mental health challenges, in addition to the undeniably growing number of students entering college with psychiatric disabilities (Raue \& Lewish, 2011; Stein, 2013).

Mental illness is highest among young adults ages 18 to 24 years, yet, this age group is least likely to seek help (Salzer, Wick, \& Rogers, 2008; Walter, 2015). Even for students who try to seek assistance, counseling services at large public universities are known to incur long wait lists for care, and these students are not receiving the mental health services 
needed to support them in both higher education and adult life (American College Health Association, 2015; Brown, 2016; Eisenberg et al., 2009; Eisenberg, Gollust, Golberstein, \& Hefner, 2007; Wynaden, Wichmann, \& Murray, 2013).

Of particular concern is the $86 \%$ of students with mental illness who withdraw from college prior to completing a degree, because a lack of education significantly limits employment opportunities and has long-term consequences for income and health (Collins \& Mowbray, 2008; Eisenberg et al., 2009; Salzer et al., 2008). With such significant attrition rates, it is apparent that universities are not providing the necessary supports to help students with mental illness succeed. Despite advances in legislation and efforts to promote inclusion, individuals with psychiatric disabilities "remain largely disenfranchised from higher education" and face both system barriers and disparities in participation (Collins \& Mowbray, 2005, p. 306; Hammel, McDonald, \& Frieden, 2016; Kranke, Jackson, Taylor, Anderson-Fye, \& Floersch, 2013; Murray, Lombardi, \& Kosty, 2014).

\section{MENTAL ILLNESS AND ACADEMIC PERFORMANCE}

For the educational system to be serving its mission "to promote student achievement and preparation for global competitiveness by fostering educational excellence and ensuring equal access," it must indeed provide equal access to all students (U.S. Department of Education, n.d.). The current higher education system was not designed for students with disabilities or mental illnesses. It is commonly acknowledged that these individuals experience barriers to admission, transition, course completion and graduation (Best, Still, \& Cameron, 2008). This is evident in the high attrition rates and gross academic performance disparities between students with psychiatric disabilities and students without (Coduti, Hayes, Locke, \& Youn, 2016). Mental health challenges and symptoms of distress -- including heightened anxiety, difficulty concentrating, emotional dysregulation, insomnia, and elevated stress -- are common problems for many college students. This emotional and psychological distress has the potential to negatively impact educational performance, particularly for students who are also self-managing other symptoms of psychiatric disabilities and conditions (Burris, Brechting, Salsman, \& Carlson, 2009; Conley, Durlak, \& Kirsch, 2015; Countryman, 2016; Kranke et al., 2013; Kreider et al., 2015).

Research demonstrates that mental and emotional health impact academic performance in that students who experience distress are more likely to suffer academic impairment (Hunt, Eisenberg, \& Kilbourne, 2010; Keyes et al., 2012). Students with psychiatric disabilities and mental health challenges, both treated and untreated, have been shown to earn lower grade point averages (GPAs) and higher drop-out rates than their peers (Eisenberg et al., 2009). Anxiety, depression and stress are detrimental to adjustment and performance in academic, social and personal contexts (Conley et al., 2015; Zajacova, Lynch, \& Espenshade, 2005). As a population, college students with mental health concerns are at risk for experiencing life-long consequences of mental illness "because their mental illness may delay the timely attainment of developmental milestones critical to adulthood” (Kranke et al., 2013, p. 214; Ashwood et al., 2015).

Self-management of psychological distress is not actively being taught in secondary education, and students are not typically provided opportunities to gain the skills prior to transition into higher education (Cleary, Walter, \& Jackson, 2011). As a result, college students are struggling to find supports that enable course completion and contribute to positive functioning. Despite having disability accommodations or access to counseling, a student without selfmanagement skills or appropriate support may stop attending class, fail to meet degree requirements, or withdraw from college (Kiuhara \& Huefner, 2008). This projected trajectory, which can unfold when students without support fail to manage the social, academic and personal demands of college, is seen in the high drop-out rates of students with mental illness. Accordingly, "students who leave universities in poor academic standing report difficulties with anxiety, sleep, 
transition and adjustment, isolation, loneliness, and self-doubt" (Kiuhara \& Huefner, 2008, p.104).

As articulated by Cleary et al. (2011), "mental health is a foundation for the well-being and academic success of students, all colleges and universities" (p. 253). By not providing the necessary supports that enable students with mental illness to succeed, the higher education system is not upholding its central purpose of providing accessible knowledge and skills (Hunt et al., 2010).

\section{ECOLOGICAL MODEL OF COLLEGE STUDENT MENTAL HEALTH AND SUCCESS: PREVENTIVE AND RISK FACTORS}

An ecological model, particularly Bronfenbrenner's framework (1994), conceives individual, interpersonal, and institutional level factors within an existing system to explain human development and behavior (Byrd \& McKinney, 2012). The ecological model can be employed to explain the mental health and academic outcomes of college students, addressing impact from all system levels.

The individual level, part of a microsystem encompasses a student's "physical, cognitive and emotional health" (Byrd \& McKinney, 2012, p. 186). The interpersonal level, as both a microsystem and mesosystem, addresses performance in the social domain, such as success and satisfaction with social interactions. The institutional level, in both the exosystem and macrosystem, encompasses factors of the university setting, including the curricula, provided services, teaching methods and overall climate of the university. Figure 1 outlines the factors identified in the literature that facilitate and challenge mental health and student success. Subscribing to an ecological model of student mental health provides a multifaceted understanding "of the connections among health, learning, productivity, and campus structure" (American College Health Association, 2016).

\section{BARRIERS TO UTILIZATION OF SERVICES}

The structure of mental health and supportive service delivery in higher education is such that only small subsets of students receive assistance (Conley et al., 2015). "Approximately half of all college students with disabilities did not register with their campus' office for disability services" (Coduti et al., 2016, p. 94) and "only 20\% - 40\% of students who experience a mental health disorder seek treatment while in college, and this rate is even lower among students in public institutions" (Ashwood et al., 2015, p. 1; Conley et al., 2015). This suggests that an overwhelming number of students who need mental health and supportive services are not receiving them (Czyz, Horwitz, Eisenberg, Kramers, \& King, 2013). Students face barriers to the utilization of campus services, most notably the obstacles of disability and illness identity; stigma and negative perceptions about mental illness; time and preference for self-management; and knowledge and availability of services.

In order for students to receive supportive services, they must first recognize their own need for services. The two primary supports for students with disabilities at most U.S. universities are student counseling services and disability services. Students are intersectional, and therefore likely face multiple barriers that impact help-seeking behaviors and outcomes. 


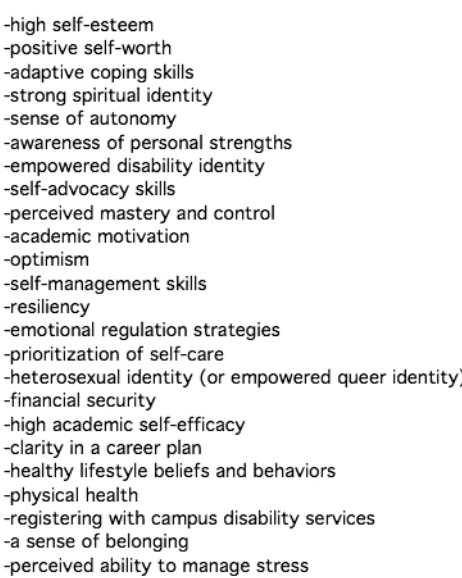

-poor coping skills

-limited emotional regulation skills

-low self-esteem

suicidal tendencies

-low motivation

-poor physical health or chronic illness

-substance use

weak disability identity

- disenfranchised sexual or gender identity

-negative attitudes and shame surrounding mental

illness

-perceived stress

-financial insecurity

-nefficient study and organization skills

-low self-efficacy (general and academic) -perceived successful social interactions

-strong friendships

-large social networks

-participation in campus organizations and activities

-family support

-strong therapeutic relationships

-positive mentorship

-engagement in support groups

-experiences of acceptance

-cultural approval of help-seeking

-positive models of empowerment or self-acceptance

-supportive peers

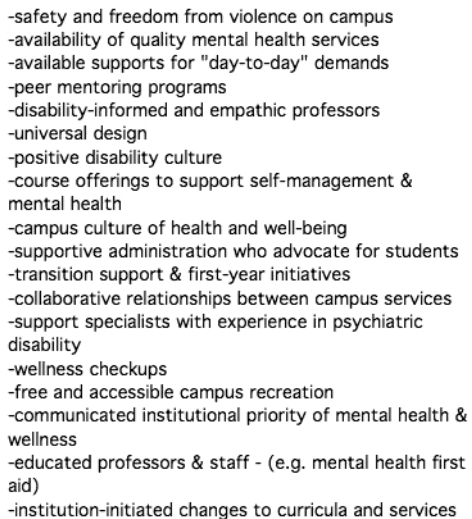

-disability-informed and empathic professors

-universal design

-positive disability culture

-course offerings to support self-management \&

mental health

-campus culture of health and well-being

-supportive administration who advocate for students

-transition support \& first-year initiatives

-collaborative relationships between campus services

-support specialists with experience in psychiatric

disability

-wellness checkups

-free and accessible campus recreation

-communicated institutional priority of mental health \&

wellness

-educated professors \& staff - (e.g. mental health first

aid)

-institution-initiated changes to curricula and services

-unsafe campus and presence of violence

-non-inclusive campus climate

-campus culture of stigma

-racially tense campus

-lack of transition support or programming

-insufficient mental health services

-low quality supportive services

-lack of professor support

-ill-informed professors and staff (mental health and

disability)

-curricula and structure that encourage competition \&

burnout

-judgement of accommodations as a crutch or

manipulation

Figure 1: Ecological model of facilitators and challenges to mental health in higher education

(Ashwood et al., 2015) (Burris et al., 2009) (Byrd \& McKinney, 2012) (Cleary et al., 2011) (Coduti et al., 2016)(Collins \& Mowbray, 2008) (Conley et al., 2015) (Davidson \& Locke, 2010)(Eisenberg, Speer, \& Hunt, 2012) (Fink, 2014) (Garza, Bain, \& Kupczynski, 2014) (Hyun, Quinn, Madon, \& Lustig, 2006) (Kiuhara \& Huefner, 2008) (Kreider et al., 2015) (Melnyk et al., 2014) (Murray et al., 2014) (Salzer et al., 2008) (Schindler et al., 2015) (Wolf et al., 2014) (Yamaguchi et al., 2013) (Zajacova et al., 2005)

\section{Disability Identity}

Students who receive support from disability services must first identify as having a disability. Accommodations are legally afforded to students who can demonstrate that their mental health "interferes with major life activities," including learning-related activities (Section 504 of Rehab Act, 1973; Americans with Disabilities Act, 1990). However, disability is a nuanced social construct, and an empowered consciousness is often shaped through exposure to disability studies or disability advocacy groups. Consequently, students with mental illness do not always identify as having a disability, even if their experience authorizes legal supports. This is further complicated by the reality that many psychiatric conditions 
manifest during the college years, inhibiting the development of a disability identity, self-advocacy skills, or help-seeking upon starting college (Coduti et al., 2016).

The literature shows that students "may perceive the disability services office as reserved for people with physical disability," limiting their receipt of beneficial supportive services they may be legally entitled to (Collins \& Mowbray, 2008, p. 92). In order to receive disability services, a student must disclose disability status, which would necessitate the acknowledgement, or identification, of mental illness as a disability (i.e., disability identity; Kiuhara \& Huefner, 2008). Even among students who do identify as having a disability, the process of disclosing and demonstrating disability status can serve as a barrier, particularly considering the difficulty of proving substantial impact on life activities "even after corrective measures have been adopted, such as medication, to ameliorate the effects of the disability" (Kiuhara \& Huefner, 2008, p. 110; Kreider et al., 2015; Coduti et al., 2016).

Higher education instigates an abrupt shift in responsibility for students as they become responsible for all aspects of the student and young adult role, including daily activities, academic performance, and management of illness or disability (including disclosure and accommodations; Cleary et al., 2011; Kreider et al., 2015). Students may not be accustomed to initiating support relationships, and therefore do not seek out services on their own. Throughout primary and secondary education, individualized education plans facilitate continuity of care and the school serves as the manager of support delivery. Higher education marks a shift to the student as the sole manager of supports, however the student is most likely without formal transition guidance, self-advocacy skills or a clear knowledge of the impending responsibility (Murray et al., 2014). Cuduti et al. (2016) articulates the student experience: "For many students, navigating the bureaucracy involved in establishing that they have a disability is a new and formidable challenge, because their high schools likely were responsible for coordinating many of these services previously" (Coduti et al., 2016, p. 289).

\section{Stigma and Perceptions of Mental Illness}

A common barrier to help-seeking among college students is the normalization of stress and the perception that help is not needed (Czyz et al., 2013). As previously articulated, the seeking and provision of services is predicated on student recognition of a need for services. It is common for college students to have the expectation of stress -- and to witness peers experiencing stress -- contributing to the perception that distress is a normal part of the college experience. Students often question the severity of their needs, even students who experience anxiety and depression. These students may "view treatment as acceptable and helpful, but not urgent or essential" (Eisenberg, Speer, \& Hunt, 2012, p. 712). Salzer, Wick and Rogers (2008) found that the most commonly reported reason for not receiving supports was the perception that they aren't needed.

Additionally, students are burdened with overcoming societal, institutional, interpersonal and self-stigma surrounding both mental illness and disability (Yamaguchi et al., 2013; Salzer et al., 2008; Murray et al., 2014). In a study by Salzer, Wick and Rogers (2008), “30\% [of students] reported not requesting accommodations because they did not want to disclose their disability to teachers, 19\% did not want to disclose their disability to other students, 30\% were fearful of being stigmatized by teachers, and 20\% were fearful of being stigmatized by other students" (p.372). These fears were validated among the students who did obtain academic support, considering 56\% of them reported embarrassment or discomfort after disclosing to faculty, and almost half felt that faculty were uncooperative or unreceptive to their needs (Salzer et al., 2008).

This highlights another barrier to utilization of services - perception of receptiveness and usefulness. If students do not believe that faculty will be approachable, receptive, and willing to implement useful accommodations to improve 
academic accessibility, then the likelihood of seeking services is low. Additionally, if students believe that faculty will perceive them differently, and discriminate accordingly, they will not be likely to seek needed supports. Students' fears and beliefs are not unsubstantiated, as "professors or instructors may tend to perceive students with mental illness as trying to manipulate them or the university system" (Kiuhara \& Huefner, 2008, p. 105). In particular, graduate students may fear professional consequences as a result of disclosing mental illness. Subsequently, they do not seek services and may suffer heightened mental health symptoms that have grave personal and professional repercussions (Gold, Andrew, Goldman, \& Schwek, 2016).

A prominent stigma-informed judgement is that accommodations and services are an unfair advantage. Students report the desire to receive academic credit in the same manner as their peers, failing to acknowledge their needs as deserving of rightfully afforded accommodations (Coduti et al., 2016). The higher education system was not universally designed, and accommodations are intended to provide equal access to the curriculum without interfering with core learning objectives. Therefore, accommodations may change the means in which students obtain knowledge, or the manner in which they demonstrate this knowledge, but they do not change the standard of learning criteria for course completion. Professors and peers of students with disabilities may view accommodations as an academic crutch that deems students with disabilities as undeserving of the same grades as students without accommodations (Kranke et al., 2013). Consequently, students may not request needed accommodations, fall behind academically, and follow the path of the $86 \%$ of students with mental illness who drop out of college.

A large subset of students is in need of mental health services but does not qualify for disability services. Campus support for these students can be provided by student counseling centers. To receive campus mental health services, a student does not need to identify as having a disability or illness; any student can legally seek campus counseling services. However, stigma continues to impact the utilization of mental health services (Yamaguchi et al., 2013). Students may fear being seen by peers at the counseling center or inflict self-judgement and guilt for experiencing distress. Students may also internalize family, cultural or religious beliefs that deter help-seeking (Cheng, Kwan, \& Sevig, 2013).

\section{Time and Preference for Self-Management}

Students have also identified a host of personal reasons, such as lack of time and preference for self-management and self-reliance, as barriers to service utilization (Czyz et al., 2013; Eisenberg et al., 2012). Exercising new-found independence and asserting autonomy is characteristic of this developmental period, however, students are not typically taught self-management skills before entering college and are thus ill-prepared to handle the copious stressors independently (Czyz et al., 2013; Cleary et al., 2011). The perception of "not enough time" is rooted in a failure to prioritize mental health, perhaps internalized from societal devaluation of positive mental health and self-care.

\section{Knowledge and Availability of Services}

The fortunate students who overcome the identity, stigma, and personal barriers to help-seeking continue to face additional barriers to receiving quality supports that enable mental well-being and academic success. Once students recognize the need to receive support, they must first have knowledge about available campus resources. As previously explained, some students with psychiatric disabilities harbor misconceptions that disability services solely serve students with physical disabilities (Collins \& Mowbray, 2008). Additionally, the scope of available campus supports may be unknown to students, as might the physical location of supportive services. 
After students become aware of campus services, the limitation of sufficient and quality care persists. "The necessary types of services in post-secondary settings are limited at best and may lack the staff expertise and staffing numbers to provide assistance in managing a disability" (Coduti et al., 2016, p. 289). As students with mental illness become more prominent on campus, universities inherit the responsibility of supporting the growing need through supportive services. Insufficient staff, unqualified providers, and lack of financial investment in mental health programming are existing obstacles (Watkins, Hunt, \& Eisenberg, 2012). According to the Midwestern Higher Education Compact, "the increased prevalence of mental health issues among college students, the greater utilization of counseling services, and the lack of staffing to meet these needs" has forced campus mental health providers to refer students elsewhere or place them on wait lists for care (Francis \& Horn, 2016, p.8).

It is imperative that institutions address the barriers to service utilization, particularly because "when student-specific supports are provided, students with disabilities succeed at levels commensurate with their abilities and to the same degree as other students. Not seeking needed supports has been found to be associated with reduced grade point averages and early withdrawal" (Salzer et al., 2008, p. 374).

The burgeoning literature on college student health reflects the student experience, acknowledging the impact of stress; psychological and emotional difficulty; health behaviors and meaningful engagement; isolation; transitions; and individual factors as paramount concerns to be targeted.

\section{EXISTING EVIDENCE-BASED INTERVENTIONS}

Students are currently being supported by campus counseling centers, wellness and health promotion services, disability services, stigma reduction initiatives, and in some instances, supported education programs. These services provide evidenced-based interventions that aim to improve student mental health.

The primary source of mental health care for university students is the campus counseling center. Students are typically afforded a limited number of individual counseling sessions over their academic career, provided by psychologists, mental health counselors and social workers (Eells \& Rando, 2010, p. 43). The sessions are guided by the theoretical orientation that shapes each individual counselor's therapeutic style, but the service is most often rooted in an individual psychotherapy framework that emphasizes factors of the student's thoughts, emotions and experiences (Eells $\&$ Rando, 2010). The aspects of counseling interventions that demonstrate the greatest effectiveness for college students are cognitive behavioral therapies, group therapies, mindfulness-based interventions, and strong supportive therapeutic relationships (Monti, Tonetti, \& Ricci Bitti, 2014; Dickson \& Gullo, 2015; Keng, Smoski, \& Robins, 2011).

Strengths of counseling that have enabled it to endure as the primary model of mental health care are: The opportunity to deliver many evidence-based interventions, proven reduction in psychiatric symptoms as a result of interventions, availability of highly trained mental health professionals in academic settings, presence of services on campus, and the common knowledge of counseling as an intervention for psychological and emotional distress (Francis \& Horn, 2016). Kranke et al. (2013) describes the positive impact of counseling services, emphasizing that students "were thriving academically because the treatment allowed them to focus on their school work and minimized problematic symptoms that were distracting" (p. 225).

The limitations of counseling relate to staff burnout; shortages of funding and available therapists to treat the growing number of students with mental health concerns; a limited number of afforded sessions that precludes consistent mental health care; a structured scope of practice that does not provide opportunities for supervised skills practice or function in real-life contexts; and the ability to reach only a "small segment of the population" (Conley et al., 
2015, p. 487; Kreider et al., 2015; Watkins et al., 2012). While counseling is highly dominant in universities and society, less traditional delivery models may help reach a larger scope of individuals to include those not being served by the counseling model (Kazdin \& Rabbitt, 2013).

Universal mental health promotion and wellness initiatives often employ a public health framework to address social and environmental risk factors by providing wellbeing resources that reach all, or a robust portion, of the student population (Davidson \& Locke, 2010). Universal mental health promotion asserts that "society is best served by assisting all of us in maintaining mental health, rather than trying to foresee which of us is most likely to act out when mental health support is not readily available" (Oslund, 2014). Universal mental health promotion is supported in literature through curricular changes, course offerings, wellness centers, integration of wellness into student programming, all of which communicate an institutional priority of mental health and wellness and have the potential to reach a large subset of students who might otherwise be unlikely to seek conventional services (Kazdin \& Rabbitt, 2013).

Health promotion and wellness initiatives, however, do not typically provide opportunities for supervised skills practice or the development of supportive therapeutic relationships, and instead, provide free education or resources. Initiation of curricular changes and course offerings is one potential way to implement a universal mental health promotion model while still providing opportunities for skills practice and supportive relationships.

Stigma-reduction initiatives aspire to cultivate accepting campus climates that do not discriminate against students with mental illness. While the campaigns are not completely in vain, the most successful interventions for changing stigmatizing attitudes and behaviors incorporate social contact with individuals with mental illness and demonstrate positive examples of what it means to live with a mental illness (Yamaguchi et al., 2013).

Moreover, a considerable body of research illustrates the effectiveness of supported education in assisting students with psychiatric disabilities through higher education (Best, Still, \& Cameron, 2008; Manthey, Goscha, \& Rapp, 2015; Schindler, Cajiga, Aaronson, \& Salas, 2015; Collins \& Mowbray, 2008). These programs have the potential to provide necessary individualized supports that enable course completion, increase retention rates, and instigate productive postgraduation outcomes (Manthey, Goscha, \& Rapp, 2015). However, "supported education programs are still few in number and there is a lack of availability of these programs for the majority of folks diagnosed with a psychiatric disability who wish to pursue education" (Manthey et al., 2015, p. 246).

Current literature articulates the potential of program development in college mental health services, acknowledging that "a critical aspect to reducing the burden of mental illness is the ability of effective interventions to reach those in need of services" (Kazdin \& Rabbitt, 2013, p. 171). Rethinking traditional models of practice and implementing innovative programs and services to address unmet mental health needs could have substantial impact on college students and society.

With increased societal attention to the strong impact of mental health, organizations and universities have instigated innovative initiatives to build programs that support students. Mental Health America formed the first ever Collegiate Mental Health Innovation Council (CMHIC) to build a forum of students who are "moving beyond awareness and taking action to address mental health in their campus communities" (Davis, 2017). Forums like CMHIC, Active Minds, NAMI, JED, and ACHA are actively working to address the unmet needs of college students and cultivate campus communities that prioritize mental health. 


\section{BENEFITS AND CHALLENGES TO SERVICE IMPLEMENTATION}

Completion of higher education is associated with greater potential for career earnings and more positive overall health outcomes. Students with mental illness face great barriers to succeeding in higher education, often resulting in withdrawal from academic pursuits. Low educational attainment poses a profound risk for unemployment, poor health, and consequently, increased dependence on public entities (Eisenberg et al., 2009). Thus, a lack of investment in campus mental health and supportive programs is a national economic and public health issue. "College campuses should be able to further their central educational missions, and generate significant economic returns for society, by investing in mental health resources" (Eisenberg et al., 2009, p. 29). The substantial benefits of mental health program development and support service implementation can be outlined using an ecological model.

At the individual (microsystem) level, increased services are protective against the exacerbation of symptoms, suicidal behavior and academic impairment for all students, not just those with diagnosed mental illness or disability (Keyes et al., 2012). Providing quality supportive services would enable students to participate productively in their academic careers and thus, graduate with useful skills (e.g., career, social, self-management) for employment. Sufficient supportive campus services can directly impact an individual by reducing the likelihood of suicide or long-term mental health-related consequences, increasing opportunities for educational attainment and social connection, and improving employment, income and health outcomes (Eisenberg et al., 2009; Ashwood et al., 2015; Cleary et al., 2011; Kranke et al., 2013; Hunt et al., 2010; Francis \& Horn, 2016). According to Ashwood et al., (2015) the investment in campus mental health services ascertains that "more students will use mental health services, more students will graduate after receiving services, and these additional graduates will see increased lifetime earnings" (p. 8).

The Institutional (exosystem and macrosystem) impact of service provision is higher graduation rates, a safer and more positive campus for all students, greater student and faculty satisfaction, and the continued stream of tuition from students who remain in college due to supportive services (Ashwood et al., 2015; Watkins et al., 2012; Byrd \& McKinney, 2012).

The Societal (macrosystem) benefits are significant. An investment in campus mental health programs has the potential to instigate large economic returns. One estimate by Ashwood et al. (2015) suggests that an additional 329 students in California could graduate as a result of increased investment in mental health programming, generating $\$ 140,715,038$ in combined lifetime earnings. They also demonstrated a net societal benefit of $\$ 56.1$ million for one state to invest in programming, describing that "for each dollar invested in mental health initiatives for college and university students, \$6.49 returns to society and \$.98 to the state government" (Ashwood et al., 2015, p. 7). "Kessler et al. (1995) points out that 'we cannot afford to forgo the opportunity to develop early interventions and treatments to prevent these costly consequences for society and some of its most vulnerable citizens" (as cited in Kranke et al., 2013, p. 215).

Increased mental health programming also has the potential to alter the societal perception of individuals with mental illness. If students with mental illness are graduating from college, obtaining gainful employment, and functioning as healthy and productive members of society, then the stigma surrounding mental illness will diminish. Additionally, program development carves out an opportunity to "engage large numbers of students who can be accessed during a critical phase of their life, and thereby address a significant public health problem among late adolescents and young adults" (Cleary et al., 2011, p. 253).

Despite the sizeable potential impact, the development of programs for college students with mental health concerns is not without challenges. One of the largest barriers is insufficient funding, complicated by a government administration 
that devalues public programs and imposes on the civil rights of many (notably, students with disabilities; Manthey et al., 2015; Sargrad, 2017). Investment in mental health and supportive programming has been demonstrated to have extensive individual, institutional and societal benefits. However, universities will face barriers to implementation without the backing of government agencies that prioritize student mental health.

Currently, universities are failing to meet the needs of students with mental health concerns. With $86 \%$ of students with mental illness dropping out, it is incontestable that the current structure of service provision is insufficient. One challenge that counseling centers face is the unavailability of qualified service providers, likely due to limited funding. Another barrier is the limited scope of available services. Mental health counseling, psychology and psychiatry are instrumental in improving symptoms, emotional regulation and outcomes for individuals with mental illness. Disability specialists can be facilitators of equal access for individuals with psychiatric disabilities. However, students report feeling " as if there were fewer supports for dealing with their more basic day-to-day demands" and desired an increased emphasis on organization, life skills, social competency and functioning in the student role (Kreider et al., 2015, p. 6).

Institutions of higher education in the United States "are recognizing with greater clarity that they cannot educate the minds of their students without attending to the health of those same minds" (Eells \& Rando, 2010, p. 43). It has been clearly demonstrated that more comprehensive services will be needed to support students with mental health concerns succeed in higher education, and innovative institutional, curricular and service developments will be instrumental in cultivating healthy academic communities (Manthey et al., 2015). 


\section{REFERENCES}

American College Health Association. (n.d.). Mission Statement \& Core Values. Retrieved from http://acha.org/About

American College Health Association. (2015). American College Health Association College Health Assessment Reference Group Executive Summary- Fall 2015. Hanover, MD.

American College Health Association. (2016). Ecological Model. Retrieved from: https://www.acha.org/HealthyCampus/HealthyCampus/Ecological_Model.aspx

Ashwood, J. S., Stein, B. D., Briscombe, B., Sontag-Padilla, L. M., Woodbridge, M. W., May, E., ... Burnam, M. A. (2015). Payoffs for California college students and taxpayers from investing in student mental health. Retrieved from https://www.rand.org/pubs/research_reports/RR1370.html. https://doi.org/10.7249/RR1370

Best, L. J., Still, M., \& Cameron, G. (2008). Supported education: Enabling course completion for people experiencing mental illness. Australian Occupational Therapy Journal, 55(1), 65-68. https://doi.org/10.1111/j.1440-1630.2007.00690.x

Bronfenbrenner, U. (1994). Ecological models of human development. International Encyclopedia of Education, 3(2), 1643-1647.

Brown, J. (2016). Anxiety and depression: Anxiety the most common mental health diagnosis in college students. Retrieved from https://www.bu.edu/today/2016/college-students-anxiety-and-depression/

Burris, J. L., Brechting, E. H., Salsman, J., \& R., Carlson (2009). Factors associated with the psychological wellbeing and distress of university students. Journal of American College Health, 8481(July). https://doi.org/10.3200/JACH.57.5.536-544

Byrd, D. R., \& McKinney, K. J. (2012). Individual, interpersonal, and institutional level factors associated with the mental health of college students. Journal of American College Health, 60(3), 185-193. https://doi.org/10.1080/07448481.2011.584334

Cheng, H.-L., Kwan, K.-L. K., \& Sevig, T. (2013). Racial and ethnic minority college students' stigma associated with seeking psychological help: Examining psychocultural correlates. Journal of Counseling Psychology, 60(1), 98-111. https://doi.org/10.1037/a0031169

Cleary, M., Walter, G., \& Jackson, D. (2011). "Not always smooth sailing": Mental health issues associated with the transition from high school to college. Issues in Mental Health Nursing, 32(January 2017), 250-254. https://doi.org/10.3109/01612840.2010.548906

Coduti, W. A., Hayes, J. A., Locke, B. D., \& Youn, S. J. (2016). Mental health and professional help-seeking among college students with disabilities. Rehabilitation Psychology, 61(3), 288-296.

https://doi.org/10.1037/rep0000101

Collins, M. E., \& Mowbray, C. T. (2008). Students with Psychiatric Disabilities on Campus: Examining Predictors of Enrollment with Disability Support Services. Journal of Postsecondary Education and Disability, 21(2), 91-104. Retrieved from http:/ files.eric.ed.gov/fulltext/EJ822096.pdf

Conley, C. S., Durlak, J. A., \& Kirsch, A. C. (2015). A meta-analysis of universal mental health prevention programs for higher education students. Prevention Science: The Official Journal of the Society for Prevention Research, 16(4), 487-507. https://doi.org/10.1007/s11121-015-0543-1 
Countryman, J. (2016). Supported education: Examining the evidence. Retrieved January 1, 2016, from https://cafetacenter.net/2016/03/supported-education-examining-the-evidence/

Czyz, E. K., Horwitz, A. G., Eisenberg, D., Kramers, A., \& King, C. A. (2013). Self-reported Barriers to Professional Help Seeking Among College Students at Elevated Risk for Suicide. Journal of American College Health, 61(7), 398-406. https://doi.org/10.1080/07448481.2013.820731.

Davidson, L., \& Locke, J. H. (2010). Using a public health approach to address student mental health. In J. Kay \& V. Schwartz (Eds.), Mental Health Care in the College Community (pp. 267-286). West Sussex, UK: John Wiley \& Sons. https://doi.org/10.1002/9780470686836.ch14

Davis, K. (2017). Meet the 15 students changing mental health on campus. Retrieved from http://www.mentalhealthamerica.net/blog/meet-15-students-changing-mental-health-campus

Dickson, J. M., \& Gullo, M. J. (2015). The role of brief CBT in the treatment of anxiety and depression for young adults at a UK university: A pilot prospective audit study. The Cognitive Behaviour Therapist, 8, 1-9. https://doi.org/10.1017/S1754470X15000240

Eells, G. T., \& Rando, R. A. (2010). Components of an Effective College Mental Health Service. In J. Kay \& V. Schwartz (Eds.), Mental Health Care in the College Community (pp. 43-55). West Sussex, UK: John Wiley \& Sons. https://doi.org/10.1002/9780470686836.ch4

Eisenberg, D., Golberstein, E., Hunt, J. B., Eisenberg, D., Golberstein, E., \& Hunt, J. B. (2009). Mental Health and Academic Success in College. The B. E. Journal of Economic Analysis \& Policy Contributions College, 9(1), 1-35. https://doi.org/10.2202/1935-1682.2191

Eisenberg, D., Gollust, S. E., Golberstein, E., \& Hefner, J. L. (2007). Prevalence and correlates of depression, anxiety, and suicidality among university students. The American Journal of Orthopsychiatry, 77(4), 534-542. https://doi.org/10.1037/0002-9432.77.4.534

Eisenberg, D., Speer, N., \& Hunt, J. B. (2012). Attitudes and Beliefs About Treatment Among College Students With Untreated Mental Health Problems. Psychiatric Services, 63(7), 711-713. https://doi.org/10.1176/appi.ps.201100250

Francis, P.C., Horn, A.S. (2016). Campus-based practices for promoting student success: Counseling services. Retrieved from: http://www.mhec.org/sites/mhec.org/files/201602counseling_services.pdf

Gold, K. J., Andrew, L. B., Goldman, E. B., \& Schwenk, T. L. (2016). "I would never want to have a mental health diagnosis on my record": A survey of female physicians on mental health diagnosis, treatment, and reporting. General Hospital Psychiatry, 43, 51-57. https://doi.org/10.1016/j.genhosppsych.2016.09.004

Hammel, J., McDonald, K. E., \& Frieden, L. (2016). Getting to inclusion: people with developmental disabilities and the Americans With Disabilities Act Participatory Action Research Consortium. Inclusion, 4(1), 6-15. https://doi.org/10.1352/2326-6988-4.1.6

Hunt, J., Eisenberg, D., \& Kilbourne, A. M. (2010). Consequences of receipt of a psychiatric diagnosis for completion of college. Psychiatric Services (Washington, D.C.), 61(4), 399-404.

https://doi.org/10.1176/appi.ps.61.4.399

Kazdin, A. E., \& Rabbitt, S. M. (2013). Novel Models for Delivering Mental Health Services and Reducing the Burdens of Mental Illness. Clinical Psychological Science, 1(2), 170-191.

https://doi.org/10.1177/2167702612463566 
Keng, S. L., Smoski, M. J., \& Robins, C. J. (2011). Effects of mindfulness on psychological health: A review of empirical studies. Clinical Psychology Review, 31(6), 1041-1056. https://doi.org/10.1016/j.cpr.2011.04.006

Keyes, C. L., Eisenberg, D., Perry, G. S., Dube, S. R., Kroenke, K., Dhingra, S. S. (2012). The relationship of level of positive mental health with current mental disorders in predicting suicidal behavior and academic impairment in college students. Journal of American College Health, 60(2), 126-133. https://doi.org/10.1080/07448481.2011.608393

Kiuhara, S. A., \& Huefner, D. S. (2008). Students with psychiatric disabilities in higher education settings: The Americans with Disabilities Act and beyond. Journal of Disability Policy Studies, 19(2), 103-113. https://doi.org/10.1177/1044207308315277

Kranke, D., Jackson, S. E., Taylor, D. A., Anderson-Fye, E., \& Floersch, J. (2013). College student disclosure of non-apparent disabilities to receive classroom accommodations. Journal of Postsecondary Education and Disability, 26(1), 35-51. Retrieved from https://case.edu/medicine/bioethics/media/school-of-

medicine/bioethics/documents/College-student-disclosure-of-non-apparent-disabilities-to-receive.pdf

Kreider, C. M., Bendixen, R. M., \& Lutz, B. J. (2015). Holistic needs of university students with invisible disabilities: a qualitative study. Physical and Occupational Therapy in Pediatrics, 35(4), 426-441. https://doi.org/10.3109/01942638.2015.1020407

Manthey, T. J., Goscha, R., \& Rapp, C. (2015). Barriers to supported education implementation: Implications for administrators and policy makers. Administration and Policy in Mental Health and Mental Health Services Research, 42(3), 245-251. https://doi.org/10.1007/s10488-014-0583-z

Monti, F., Tonetti, L., \& Ricci Bitti, P. E. (2014). Comparison of cognitive-behavioural therapy and psychodynamic therapy in the treatment of anxiety among university students: an effectiveness study. British Journal of Guidance \& Counselling, 42(3), 233-244. https://doi.org/10.1080/03069885.2013.878018

Murray, C., Lombardi, A., \& Kosty, D. (2014). Profiling adjustment among postsecondary students with disabilities: A person-centered approach. Journal of Diversity in Higher Education, 7(1), 31-44. https://doi.org/10.1037/a0035777

Oslund, C. (2014). Supporting college and university students with invisible disabilities: A guide for faculty and staff working with students with autism, AD/HD, language processing disorders, anxiety, and mental illness. London UK: Jessica Kingsley Publishers

Raue, K., \& Lewish, L. (2011). Students with disabilities at degree-granting postsecondary institutions: First look. Retrieved from https://nces.ed.gov/pubs2011/2011018.pdf

Salzer, M. S., Wick, L. C., \& Rogers, J. A. (2008). Familiarity with and use of accommodations and supports among postsecondary students with mental illnesses. Psychiatric Services (W ashington, D.C.), 59(4), 370-375. https://doi.org/10.1176/appi.ps.59.4.370

Sargrad, S. (2017). A danger to students with disabilities. Retrieved from https://www.usnews.com/opinion/knowledge-bank/articles/2017-01-19/students-with-disabilitiesdeserve-better-than-donald-trumps-betsy-devos

Schindler, V., Cajiga, A., Aaronson, R., \& Salas, L. (2015). The experience of transition to college for students diagnosed with asperger's disorder. The Open Journal of Occupational Therapy, 3(1).

https://doi.org/10.15453/2168-6408.1129 
Stein, K. F. (2013). DSS and accommodations in higher education: Perceptions of students with psychological disabilities. Journal of Postsecondary Education and Disability, 26(2), 145-161. Retrieved from http://www.ahead.org/publications/jped

U.S. Department of Education, Mission statement. Retrieved from https://www2.ed.gov/about/landing.jhtml

Walter, M. (2015). “Going it alone” adds to tertiary students' high mental health risk. Retrieved from http:/ / theconversation.com/going-it-alone-adds-to-tertiary-students-high-mental-health-risk-41362

Watkins, D. C., Hunt, J. B., \& Eisenberg, D. (2012). Increased demand for mental health services on college campuses: Perspectives from administrators. Qualitative Social Work, 11(3), 319-337. https://doi.org/10.1177/1473325011401468

Wynaden, D., Wichmann, H., \& Murray, S. (2013). A synopsis of the mental health concerns of university students: Results of a text-based online survey from one Australian university. Higher Education Research \& Development, 32(5), 846-860. https://doi.org/10.1080/07294360.2013.777032

Yamaguchi, S., Wu, S.-I., Biswas, M., Yate, M., Aoki, Y., Barley, E. A., \& Thornicroft, G. (2013). Effects of shortterm interventions to reduce mental health-related stigma in university or college students: a systematic review. The Journal of Nervous and Mental Disease, 201(6), 490-503.

https://doi.org/10.1097/NMD.0b013e31829480df

Zajacova, A., Lynch, S. M., \& Espenshade, T. J. (2005). Self-efficacy, stress, and academic success in college. Research in Higher Education, 46(6), 677-706. https:/ / doi.org/10.1007/s11162-004-4139-z

Please address author correspondence to:

Leah Goodman, MA, OTR/L

1919 W Taylor St

306 AHSB, Mail Code 811

Lgoodm2@uic.edu

LeahGoodman91@gmail.com

\section{Author Note \& Acknowledgements}

This manuscript is based on a literature review that was conducted as part of an occupational therapy clinical doctorate field exam defense. The author wishes to acknowledge Dr. Joy Hammel, Dr. Celeste Januszewski, and Dr. Carlin Daley for their guidance and support as a committee. 